\title{
Erratum to: Gestational Diabetes and Subsequent Growth Patterns of Offspring: The National Collaborative Perinatal Project
}

\author{
Kesha Baptiste-Roberts • Wanda K. Nicholson • \\ Nae-Yuh Wang · Frederick L. Brancati
}

Published online: 10 November 2011

(C) Springer Science+Business Media, LLC 2011

\section{Erratum to: Matern Child Health J \\ DOI 10.1007/s10995-011-0756-2}

There was an error on Table 4 describing the associations between gestational diabetes and childhood overweight status at age 7 . The odds ratios and confidence intervals for the associations between gestational diabetes and childhood overweight status at age 7 in the printed manuscript read $1.68(1.31,1.16)$ and $1.61(1.07,1.28)$ and should read
1.68 (1.31, 2.16) for Model 1 and 1.17 (1.07, 1.28) respectively. The rest of the table is accurate as printed.

In addition, in the last paragraph of the results section under the subheading Association of GDM with Childhood Overweight Status, on line 3 of that paragraph, the odds ratio for the relationship between GDM and overweight status at age 7 is printed as 1.61 and should be 1.17 .

The author regrets this error.

The online version of the original article can be found under doi:10.1007/s10995-011-0756-2.

K. Baptiste-Roberts $(\varangle)$

School of Nursing, Penn State University, University Park, 1300

ASB/A110, 600 Centerview Drive, Hershey, PA 17033, USA

e-mail: kab50@psu.edu

K. Baptiste-Roberts

Department of Public Health Sciences, Penn State University

College of Medicine, Hershey, PA, USA

W. K. Nicholson

Department of Obstetrics \& Gynecology, University of North

Carolina, Chapel Hill, NC, USA

N.-Y. Wang · F. L. Brancati

Department of Medicine, Johns Hopkins University, Baltimore,

MD, USA

N.-Y. Wang

Department of Biostatistics, Johns Hopkins University,

Baltimore, MD, USA

F. L. Brancati

Department of Epidemiology, Johns Hopkins University,

Baltimore, MD, USA 